\title{
ANÁlise Morfológica de Sagittaria montevidensis Desenvolvida EM Diferentes Condições DE INUNDAÇÃo ${ }^{1}$
}

\author{
Morphological Analysis of Sagittaria montevidensis Developed Under Different Flooding \\ Conditions
}

\author{
CASSOL, B. ${ }^{2}$, AGOSTINETTO, D. ${ }^{3}$ e MARIATH, J.E.A. ${ }^{4}$
}

\begin{abstract}
RESUMO - O cultivo de arroz irrigado em sistema pré-germinado tem permitido o desenvolvimento de plantas daninhas aquáticas, como as da espécie Sagittaria montevidensis (sagitária), a qual desenvolveu biótipos resistentes a herbicidas inibidores de ALS, no Estado de Santa Catarina. No presente trabalho, objetivou-se examinar as respostas morfológicas de sagitária quanto à variação da lâmina d'água, crescendo sob condições ambientais controladas. Os tratamentos foram representados pelas seguintes condições de inundação: solo saturado, 5, 10 e $20 \mathrm{~cm}$ de submersão, em delineamento experimental completamente casualizado, com cinco repetições. A presença de lâmina d'água favoreceu a germinação das sementes de sagitária. O aumento da profundidade de submersão incrementou a estatura da planta por meio do alongamento dos pecíolos das folhas espatuladas e sagitadas. Variação na profundidade da lâmina d’água não modificou o número de plantas, a massa seca, o número de folhas e de raizes, o tamanho da folha linear, o tamanho da lâmina foliar espatulada e sagitada e do escapo floral das plantas de S. montevidensis. As folhas de sagitária de mesmo tipo morfológico, quando desenvolvidas nas profundidades de água testadas, não diferiram histologicamente.
\end{abstract}

Palavras-chave: germinação, manejo, níveis de água, plantas daninhas, sagitária.

ABSTRACT - The cultivation of irrigated rice under water-seeded rice system has allowed the development of aquatic weed plants such as Sagittaria montevidensis (giant arrowhead), which has developed biotypes resistant to ALS-inhibiting herbicides in the state of Santa Catarina. This research aimed to investigate the morphologic responses of giant arrowhead to water level variation, under controlled environmental conditions. The treatments were represented by the following flood conditions: saturated soil, 5, 10 and $20 \mathrm{~cm}$ of water submersion, arranged in a completely randomized design, with five repetitions. Seed germination was promoted by the presence of water. Submersion depth increased plant height through petide lengthening of the spatulate and sagittate foliar blade size leaves. Water sheet depth variation did not modify the number of plants, dry mass, the number of leaves and roots, linear leaf size, spatulate and sagittate foliar blade size and the inflorescence axis of the $\mathbf{S}$. montevidensis plants. The giant arrowhead leaves of the same morphological type did not differ histologically when developed under the tested water depths.

Keywords: germination, management, water sheets, weeds, giant arrowhead

1 Recebido para publicação em 10.11.2007 e na forma revisada em 29.5.2008.

2 Biol., M.S., Aluna do Programa de Pós-Graduação em Botânica da Universidade Federal do Rio Grande do Sul - UFRGS; ${ }^{3}$ Eng ${ }^{0}-$ Agro ${ }^{-}$, Ph.D., Prof. da Faculdade de Agronomia Eliseu Maciel da Universidade Federal de Pelotas, Caixa Postal 354, 96010-900 Pelotas-RS; ${ }^{4}$ Biol., Ph.D., Prof. do Instituto de Biociências da UFRGS, Av. Bento Gonçalves, 9500, Setor 4, Prédio 43423, Sala 206, 91591-970 Porto Alegre-RS 


\section{INTRODUÇÃO}

A região Sul é responsável por grande parte da produção total de arroz no Brasil (Sanint, 1997). O sistema predominantemente utilizado é o de irrigação com inundação controlada; entretanto, a infestação das lavouras por plantas daninhas constitui um dos principais limitantes ao potencial de produtividade do arroz. Uma alternativa para redução das infestações é o cultivo pelo sistema pré-germinado, o qual é utilizado no Estado de Santa Catarina na quase totalidade da área orizícola e no Rio Grande do Sul em cerca de $10 \%$ da área cultivada. Nesse sistema, em razão de o preparo do solo e a semeadura serem realizados com lâmina de água, há favorecimento do desenvolvimento de plantas daninhas de ambiente aquático.

As espécies de macrófitas aquáticas apresentam grande amplitude ecológica, o que lhes permite habitar ambientes alagados em diferentes gradientes físico-químicos. Entre outras espécies, Sagittaria montevidensis (sagitária) tem se destacado pelo nivel de infestação e redução da produtividade da cultura do arroz. Embora esta espécie seja considerada pouco competitiva em culturas de arroz pré-germinado, a falta de controle químico pode levar ao enriquecimento do banco de sementes, permitindo aumento na população de sagitária em níveis que afetem a produção de arroz (Gibson et al., 2001). A ocorrência de biótipos de sagitária resistentes a herbicidas inibidores da enzima ALS - acetolactato sintase (Noldin et al., 1999), os quais se constituem no principal grupo de herbicidas para controle de plantas daninhas na cultura do arroz, tem dificultado a adoção do controle químico. Experimentos demonstram a ineficácia do controle de sagitária por dez herbicidas e efeitos moderados de outros três herbicidas que atuam em outras rotas metabólicas (Noldin \& Eberhardt, 2000). Concenço et al. (2007) observaram que o ecótipo resistente de sagitária estudado apresentou emergência mais rápida, maior vigor e via de absorção aérea do herbicida preferencial em relação às raízes, quando comparado com o ecótipo suscetível. A maior adaptabilidade e a alteração em relação ao sítio de absorção do herbicida foram interpretadas como uma conseqüência indireta do(s) fator(es) responsável(is) pela resistência de sagitária aos herbicidas inibidores da ALS. Estes mesmos autores relataram a ocorrência de populações de sagitária resistentes a esses herbicidas em praticamente todos os municípios produtores de arroz irrigado em Santa Catarina, com carência de alternativas de controle eficientes.

Uma opção para controle de sagitárias é o uso de métodos biológicos, como a aplicação de herbicida fúngico. Os fungos Rhynchosporium alismatis ( $\mathrm{sin}$. Plectosporium alismatis) e $P$. tabacinium são eficazes no controle de S. pygmaea, S. guayanensis e S. trifolia, porém a utilização em campo desses mico-herbicidas é dificultada pelas limitações biológicas, tecnológicas, ambientais e econômicas (Cother \& Gilbert, 1994; Chung et al., 1998). Ainda, $S$. montevidensis se mostrou resistente a P. alismatis (Pitt et al., 2004). Assim, outros métodos de manejo são necessários para a integração de técnicas que consigam resultados sobre a comunidade infestante.

O regime hídrico envolve a soma dos efeitos da profundidade da água, duração e período de inundação e a razão entre inundação e diminuição da coluna d'água. Dos fatores ecológicos que regem o regime hídrico, a profundidade é o mais significativo no controle do desempenho e reprodução das macrófitas emergentes (White \& Ganf, 2002). A profundidade altera as características físico-químicas do meio aquático, como aumento da concentração de $\mathrm{CO}_{2}$, decréscimo da concentração de $\mathrm{O}_{2}$ e luminosidade.

O estabelecimento da planta dependerá da sua capacidade em adaptar-se morfofisiologicamente a essas condições. Modificações morfológicas, anatômicas e fenológicas nos vegetais, para aumentar ou melhorar o potencial de aeração, são a estratégia mais comum para tolerar a inundação ou a profundidade d’água. Em várias espécies, observa-se que a formação de inflorescências é tamanho-dependente. Plantas de Schoenoplectus lineolatus, quando crescidas em águas mais profundas, apresentaram colmos menores e produziram poucas inflorescências (Ishii \& Kadono, 2004). A estatura da planta também teve influência na produção de flores em Blyxa aubertii e $B$. echinosperma, havendo correlação positiva entre tamanho e número de flores. A quantidade de sementes por fruto não foi alterada pelo tamanho do indivíduo, e sim regulada pelo 
número de flores produzidas (Jiang \& Kadono, 2001a).

Os objetivos deste trabalho foram examinar as respostas morfológicas de Sagittaria montevidensis crescendo sob condições ambientais controladas quanto à variação da lâmina d'água e fornecer subsídios para a busca de métodos eficazes no manejo da cultura do arroz irrigado.

\section{MATERIAL E MÉTODOS}

A espécie utilizada foi Sagittaria montevidensis (Alismataceae). Constitui-se de ervas, com filotaxia rosulada, folhas glabras e heteromórficas, apresentando limbo linear, quando submersas, e espatulado ou sagitado, quando emersas. Inflorescência classificada como racemo, ereta e emersa. Flores actinomorfas, pediceladas, heteroclamideas e trimeras. As flores megasporangiadas estão localizadas nos verticilos inferiores e as microsporangiadas, a partir do segundo ou quinto verticilo. Fruto tipo aquênio (Rego, 1988).

O trabalho experimental foi desenvolvido utilizando-se aquênios de sagitária existentes no banco de sementes do solo coletado na Estação Experimental do Arroz do Instituto RioGrandense do Arroz (EAA-IRGA), Cachoeirinha - RS $\left(30^{\circ} \mathrm{S}, 51^{\circ} \mathrm{W}\right)$. O delineamento experimental foi completamente casualizado, com cinco repetições. Os tratamentos constaram de quatro condições de inundação: solo saturado, 5,10 e $20 \mathrm{~cm}$ de submersão em lâmina d'água. Cada unidade experimental foi composta por vaso com capacidade volumétrica de $4 \mathrm{~L}$.

As variáveis avaliadas aos 49 dias após a instalação do experimento foram: número de plantas, de folhas e de raizes; altura da planta, comprimento do escapo floral, lâmina foliar e pecíolo dos diferentes tipos morfológicos de folhas, massa seca total e caracterização morfológica e histológica das folhas e flores. Para a quantificação das variáveis, as plantas foram retiradas dos vasos com o substrato e lavadas sob água corrente.

As folhas dos diferentes tipos morfológicos foram coletadas, seccionadas e fixadas em glutaraldeído 1\% e formaldeído 4\% (McDowell \& Trump, 1976), em tampão fosfato de sódio
0,1 M (Gabriel, 1982), desidratadas em série etílica crescente (Johansen, 1940) e incluídas em hidroxietilmetacrilato (Gerrits \& Smid, 1983). As seções histológicas, com espessura de $5 \mu \mathrm{m}$, foram coradas com Azul de Toluidina 0,05\% (Feder \& O’Brien, 1968) e analisadas em microscopia óptica de campo claro. Para os testes histoquímicos foram feitas seções transversais à mão livre e utilizados os reagentes floroglucinol em HCl (Johansen, 1940), para detecção de lignina, e cloreto de zinco iodado (Jensen, 1962), para celulose.

Os dados foram submetidos à análise de variância não-paramétrica de Kruskall-Wallis. A comparação de médias foi realizada por teste de comparações múltiplas não-paramétrico.

\section{RESULTADOS E DISCUSSÃO}

A presença de lâmina d'água favoreceu a germinação das sementes de sagitária, enquanto na exposição à condição de solo saturado (nivel zero) não foi constatada a sua germinação (Tabela 1, Figura 1a). Resultados similares foram encontrados em Sagittaria latifolia (Kellogg et al., 2003) e Alisma subcordata (Moore \& Keedy, 1988), que não germinaram em solo exposto (não inundado).

O biótipo de Sagittaria montevidensis não modificou sua capacidade de germinação com o aumento do nivel da lâmina d'água (Tabela 1). $\mathrm{O}$ efeito inibitório da inundação na germinação tem sido demonstrado em diversas espécies de banhado (Nishihiro et al., 2004). Em $S$. trifolia houve maior germinabilidade no nivel zero do que nos niveis de 5 e $10 \mathrm{~cm}$ de profundidade, porém nos três níveis foi possível a sua germinação (Liu et al., 2005).

Um dos métodos recentes de manejo dos campos de arroz é a exposição do banco de sementes a longos períodos de seca, a fim de dificultar a sobrevivência das sementes (Jiang \& Kadono, 2001b). Pelos resultados obtidos, a incapacidade de germinação de $S$. montevidensis em solo saturado, na ausência de lâmina d'água, possibilita o manejo através da rotação de culturas ou drenagem na entressafra de monocultivo de arroz irrigado.

Na espécie estudada, não foi constatada diferença significativa da massa seca total com a variação do nível d'água (Tabela 1). 
Tabela 1 - Variáveis avaliadas em plantas de Sagittaria montevidensis aos 49 dias após realização dos tratamentos. UFRGS/Porto Alegre-RS, 2002

\begin{tabular}{|c|c|c|c|c|c|}
\hline Tratamento & $\begin{array}{c}\text { Planta } \\
\left(\mathrm{n}^{\circ} \mathrm{m}^{-2}\right)\end{array}$ & $\begin{array}{c}\text { Massa seca } \\
\left(\mathrm{g} \mathrm{m}^{-2}\right)\end{array}$ & $\begin{array}{c}\text { Altura } \\
(\mathrm{cm})\end{array}$ & $\begin{array}{c}\text { Folhas } \\
\left(\mathrm{n}^{-} \mathrm{planta}^{-1}\right)\end{array}$ & $\begin{array}{c}\text { Raízes } \\
\left(\mathrm{n}^{-} \mathrm{planta}^{-1}\right)\end{array}$ \\
\hline Solo saturado & $0,0 \mathrm{~b}^{*}$ & $0,0 \mathrm{~b}^{*}$ & $0,0 \mathrm{c}^{*}$ & $0,0 \mathrm{~b}^{*}$ & $0,0 \mathrm{~b}^{*}$ \\
\hline $5 \mathrm{~cm}^{1 /}$ & $94,5 \mathrm{a}$ & $21,8 \mathrm{a}$ & $20,9 \mathrm{~b}$ & $3,3 \mathrm{a}$ & $45,8 \mathrm{a}$ \\
\hline $10 \mathrm{~cm}^{1 /}$ & $86,6 \mathrm{a}$ & $23,0 \mathrm{a}$ & $28,9 \mathrm{ab}$ & $3,9 \mathrm{a}$ & $50,1 \mathrm{a}$ \\
\hline $20 \mathrm{~cm}^{1 /}$ & $78,7 \mathrm{a}$ & $21,6 \mathrm{a}$ & $36,5 \mathrm{a}$ & $4,2 \mathrm{a}$ & $60,5 \mathrm{a}$ \\
\hline
\end{tabular}

1/ Altura da lâmina d'água. *Médias seguidas de mesma letra na coluna não diferem significativamente entre si pelo teste de KruskallWallis a $5 \%$ de probabilidade.

Resposta similar foi observada em Sagittaria lancifolia, que apresentou tolerância à submersão e não teve sua biomassa alterada pela profundidade da lâmina d'água (Howard \& Mendelssohn, 1995). Da mesma forma, não foi verificada alteração de biomassa subterrânea em S. latifolia e S. platyphylla, quando expostas à profundidade de $30 \mathrm{~cm}$ de água (Martin $\&$ Shaffer, 2005). Macrófitas emergentes respondem funcionalmente à profundidade da água com o aumento da alocação de biomassa para a parte aérea, em relação às partes subterrâneas (Coops et al., 1996), ou com a diminuição da biomassa total (Paillissson \& Marion, 2006).

Nas profundidades de submersão avaliadas no trabalho $(5,10$ e $20 \mathrm{~cm})$, o número de folhas e de raízes foi similar entre os tratamentos, porém verificou-se aumento na estatura da planta à medida que a profundidade de submersão aumentou (Tabela 1, Figura 1b). O tamanho das folhas lineares, espatuladas ou sagitadas não diferiu entre tratamentos em que houve germinação das sementes. Por outro lado, o comprimento do pecíolo das folhas espatuladas e sagitadas aumentou com o incremento na profundidade de submersão (Tabela 2). Determinadas espécies, tolerantes à submersão, são distinguidas das espécies não-tolerantes pela habilidade de alongar o caule e/ou o pecíolo. Isso permite que a planta eleve-se da água e recupere o contato com a atmosfera (Armstrong et al., 1994). O aumento do tamanho do pecíolo a profundidades maiores também foi observado em Epilobium hirsutum quando exposta à submersão de $5 \mathrm{~cm}$ de profundidade, em Nymphaea alba para niveis de água variando entre 10 e $50 \mathrm{~cm}$ (Lenssen et al., 1998; Paillisson \& Marion, 2006) e em seis espécies de Sagittaria, germinadas em solo saturado e em profundidade de 4 a $27 \mathrm{~cm}$ (Wooten, 1986).

O aumento da estatura da planta, possibilitando a emergência da parte aérea, foi observado em diversas espécies de Sagittaria. $S$. sagittifolia tolerou submersão prolongada por oito semanas, através do aumento do comprimento da parte aérea (van den Brink et al., 1995). S. lancifolia respondeu à elevação do nível d'água em 7,5 e $15 \mathrm{~cm}$ por meio do aumento da altura da folha (Howard \& Mendelssohn, 1995). Quando em condições anaeróbias, $S$. pygmaea apresentou crescimento da parte aérea, através do alongamento celular, promovido pela ação do cálcio (Tamura et al., 2001). A manutenção da maior parte da superficie fotossintética acima da superficie d'água permite o transporte de oxigênio para as raízes e caules subterrâneos, evitando condições de anoxia no sedimento e possibilitando a manutenção do crescimento da planta (Brändle, 1991).

Os resultados obtidos no estudo demonstram que o alongamento do pecíolo em $S$. montevidensis compensa o aumento do nível da água sem afetar a biomassa das folhas. Provavelmente, o aumento da mobilização de nutrientes é obtido com a translocação de recursos a partir dos órgãos subterrâneos.

Em folhas de diversas macrófitas vasculares (Echinodorus tenellus, E. paniculatus e Neptunia plena) foram registradas modificações significativas quanto ao grau de lignificação dos feixes vasculares quando crescidas em ambientes com intensa variação da lâmina d'água (Resende, 1996; Scremin-Dias, 2000). 

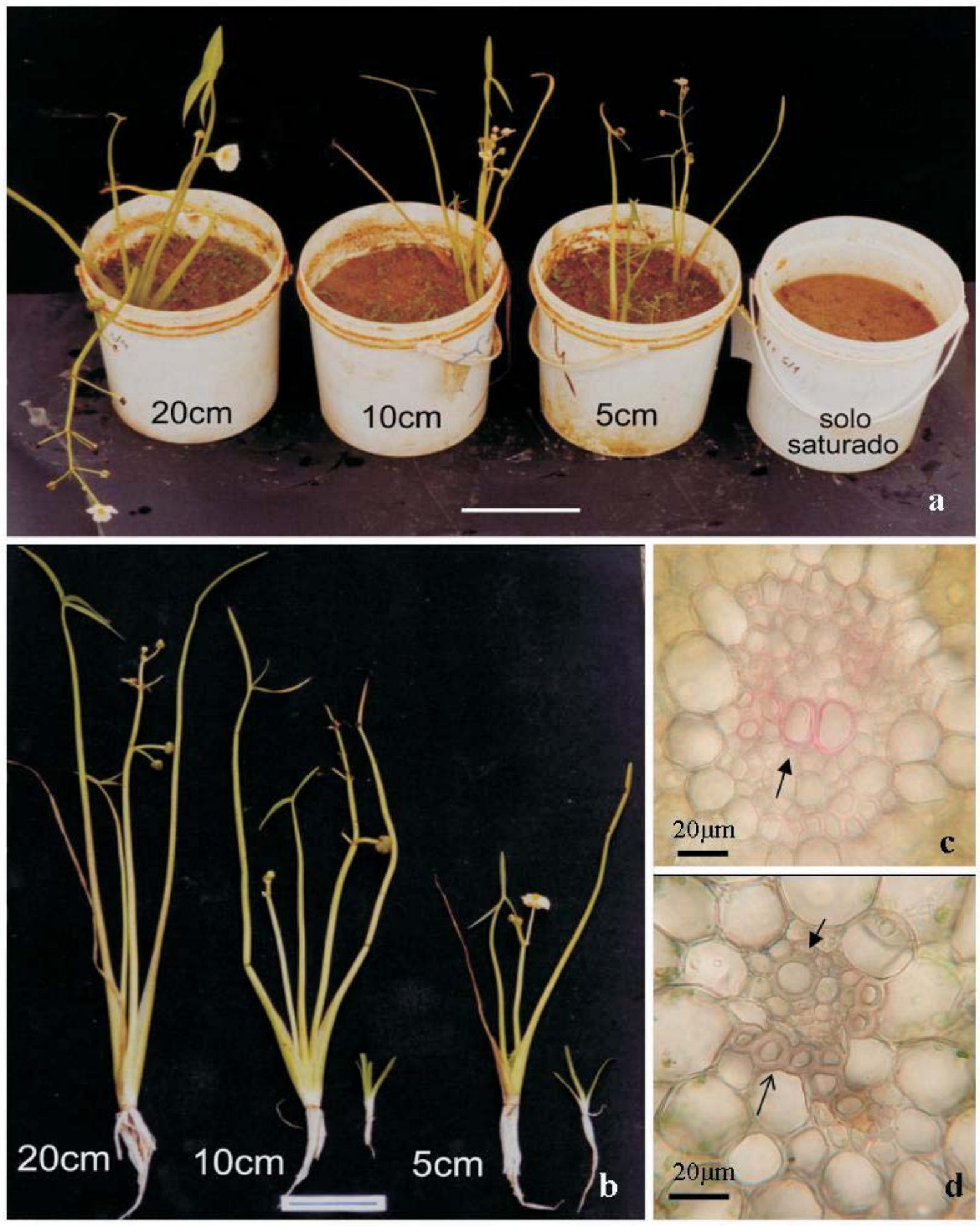

Figura 1 - Plantas de Sagittaria montevidensis germinadas nos tratamentos de 5, 10, 20 cm de submersão e solo saturado, após 49 dias do início do experimento. UFRGS/Porto Alegre-RS, 2002a). Unidade experimental dos quatro tratamentos (escala = $10 \mathrm{~cm}$ ); b) Plantas coletadas em diferentes condições de inundação, mostrando a estatura diferenciada (escala $=5 \mathrm{~cm}$ ); c) Feixe central de folha sagitada, mostrando presença de lignina nos elementos traqueais do xilema (seta); d) Feixe abaxial, na nervura mediana de folha sagitada, com detecção de celulose nas paredes do esclerênquima (seta aberta) e elementos traqueais (seta fechada). 
Tabela 2 - Variáveis avaliadas em plantas de Sagittaria montevidensis aos 49 dias após realização dos tratamentos, UFRGS/Porto Alegre-RS, 2002

\begin{tabular}{|c|c|c|c|c|c|c|}
\hline Tratamento & $\begin{array}{c}\text { Comprimento } \\
\text { da folha linear } \\
(\mathrm{cm})\end{array}$ & $\begin{array}{c}\text { Comprimento } \\
\text { do limbo da } \\
\text { folha espatulada } \\
(\mathrm{cm})\end{array}$ & $\begin{array}{c}\text { Comprimento } \\
\text { do limbo da } \\
\text { folha sagitada } \\
(\mathrm{cm})\end{array}$ & $\begin{array}{c}\text { Comprimento } \\
\text { do pecíolo da } \\
\text { folha espatulada } \\
(\mathrm{cm})\end{array}$ & $\begin{array}{c}\text { Comprimento } \\
\text { do pecíolo da } \\
\text { folha sagitada } \\
(\mathrm{cm})\end{array}$ & $\begin{array}{c}\text { Comprimento do } \\
\text { escapo floral } \\
(\mathrm{cm})\end{array}$ \\
\hline Solo saturado & $0,0 \mathrm{~b}^{*}$ & $0,0 \mathrm{~b}^{*}$ & $0,0 \mathrm{~b}^{*}$ & $0,0 \mathrm{c}^{*}$ & $0,0 \mathrm{~d}^{*}$ & $0,0 \mathrm{~b}^{*}$ \\
\hline $5 \mathrm{~cm}^{1 /}$ & $7,0 \mathrm{a}$ & $3,8 \mathrm{a}$ & $5,0 \mathrm{a}$ & $16,4 \mathrm{~b}$ & $15,2 \mathrm{c}$ & $13,2 \mathrm{a}$ \\
\hline $10 \mathrm{~cm}^{1 /}$ & $3,2 \mathrm{a}$ & $5,8 \mathrm{a}$ & $6,0 \mathrm{a}$ & $23,2 \mathrm{a}$ & $21,2 \mathrm{~b}$ & $15,6 \mathrm{a}$ \\
\hline $20 \mathrm{~cm}^{1 /}$ & $12,3 \mathrm{a}$ & $4,0 \mathrm{a}$ & $7,1 \mathrm{a}$ & $27,7 \mathrm{a}$ & $31,2 \mathrm{a}$ & $20,8 \mathrm{a}$ \\
\hline
\end{tabular}

1/ Altura da lâmina d'água. * Médias seguidas de mesma letra na coluna não diferem significativamente entre si pelo teste de KruskallWallis a $5 \%$ de probabilidade.

As folhas de Sagittaria montevidensis de um mesmo tipo morfológico, quando desenvolvidas nas profundidades de água testadas $(5,10 \mathrm{e}$ $20 \mathrm{~cm}$ ), não diferiram histologicamente. A presença de lignina foi verificada apenas nos elementos traqueais do metaxilema (Figura 1c), sendo os espessamentos das fibras pericíclicas e a extensão de bainha de constituição pectocelulósica (Figura 1d), localizadas nos bordos foliares e na nervura central das folhas mais espessas. Assim, nas condições testadas, $o$ investimento energético da planta é destinado à multiplicação e/ou alongamento celular e não à sintese de parede secundária. O alongamento celular ocorre principalmente devido à elevada pressão de turgescência das células dessas plantas, que não apresentam restrição hídrica (Kramer \& Boyer, 1995). Interpretouse esse resultado como uma adaptação ao ambiente em que a folha se desenvolve, uma vez que a coluna d'água permite a sustentação do órgão, tornando dispensável a formação de um tecido mecânico altamente diferenciado. A alocação de energia parece ser focada na emergência do órgão acima do nível da água e, conseqüentemente, no contato com a atmosfera.

Em S. montevidensis foi verificada a presença de heteroblastia no desenvolvimento foliar, com a formação de folhas lineares, seguidas da forma espatulada e, por último, da sagitada (Figura 2a). Em condições desfavoráveis para o seu estabelecimento, devido à ausência de lâmina d'água, verificou-se que a planta permanece na forma juvenil (folhas lineares), reproduzindo-se vegetativamente, através da diferenciação de gemas axilares em estolões simpodiais (Figura 2c). A cada nó, novas folhas lineares e raízes adventícias são diferenciadas (Figura 2d). A partir da ruptura do estolão, na região do entrenó, os indivíduos são isolados, permitindo a propagação clonal. A emissão dos escapos florais ocorre somente quando há a expansão da folha adulta (sagitada). Esse mesmo comportamento foi relatado por Kaul (1987) para espécies de Sagittaria (com folhas sagitadas) anuais e perenes com maior plasticidade fenotípica.

Embora não tenha havido diferença significativa no comprimento do escapo floral entre os tratamentos, observou-se que a média é sempre maior quanto maior a profundidade de submersão, dentro de cada tratamento (Tabela 2). De forma similar à resposta encontrada no pecíolo das folhas emergentes, há um alongamento do escapo floral até o contato da parte superior da inflorescência com o ar. Sagittaria é um gênero entomófilo (Pacini \& Franchi, 2000), portanto, a exposição das flores e do néctar floral à atmosfera é essencial para a realização de reprodução sexuada na espécie.

Algumas variações na expressão morfológica da tipologia da inflorescência foram observadas, como: a quantidade de flores microsporangiadas é maior que a de flores megasporangiadas em uma mesma inflorescência; as flores dos verticilos intermediários podem apresentar gineceu rudimentar; e a espécie é protogínica e com antese seqüencial (Figura 2e). Observou-se ainda que os frutos apresentam-se maduros quando todas as flores microsporangiadas já senesceram.

Casos de protoginia foram constatados em S. lancifolia subsp. lancifolia (Pimenta, 1992) e S. trifolia (Huang et al., 2002). Esta última 

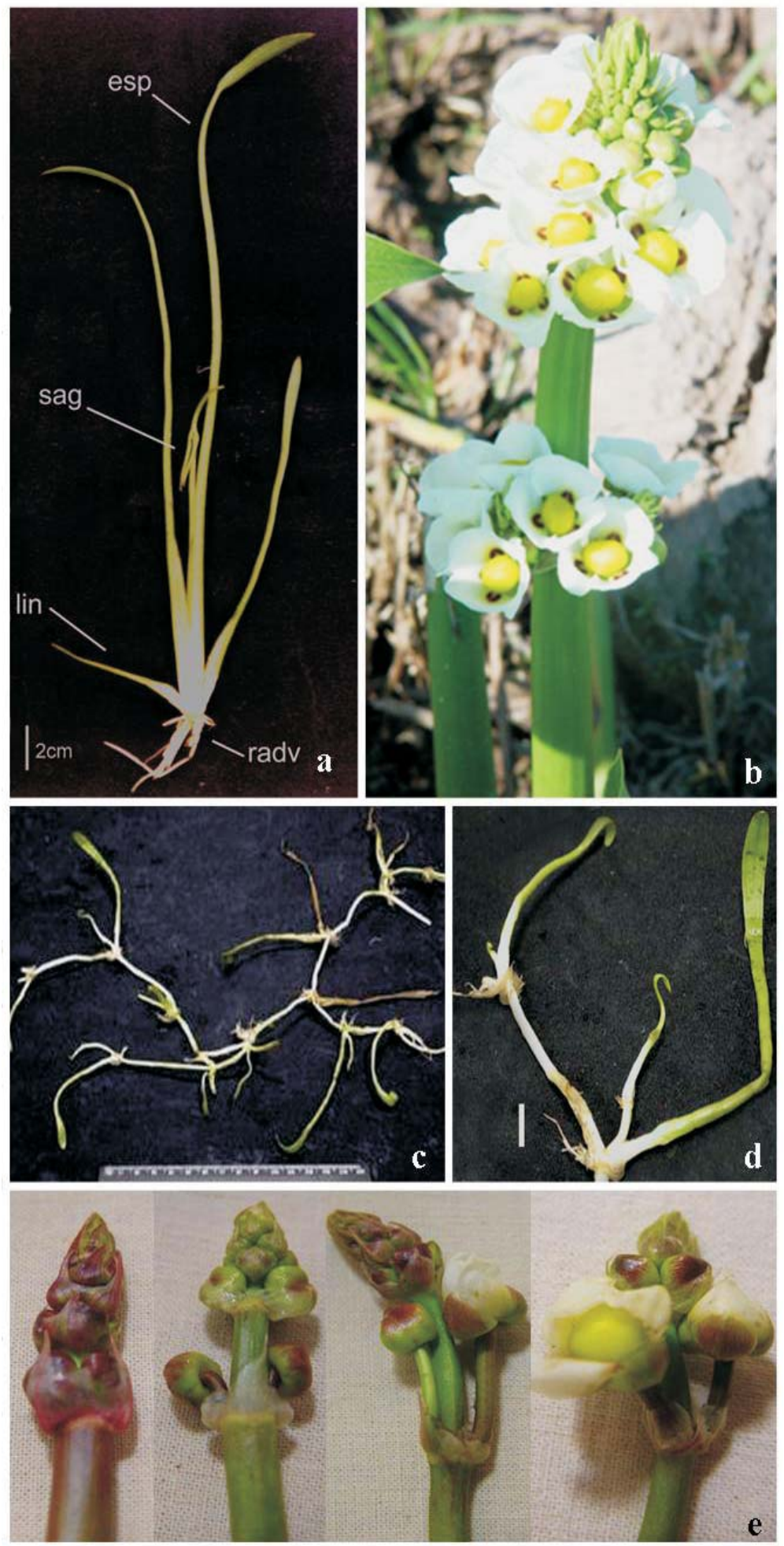

Figura 2 - Aspectos morfológicos de Sagittaria montevidensis. UFRGS/Porto Alegre-RS, 2002a). Planta com diferentes tipos foliares ( série heteroblástica, escala $=2 \mathrm{~cm}$ ); b) Inflorescência atípica, apresentando várias flores megasporangiadas; c) Desenvolvimento simpodial do estolão com morfologia juvenil; d) Porção terminal do estolão, apresentando diferenciação de raízes adventícia e folhas lineares nos nós (escala $=1 \mathrm{~cm}$ ); e) Exemplo de antese seqüencial em uma inflorescência (racemo). esp folha espatulada, lin - folha linear, sag - folha sagitada, radv - raiz adventícia. 
também apresenta abertura seqüencial dos botões florais, da base para o ápice da inflorescência. A dicogamia e antese seqüencial criam uma separação temporal de maturação dos esporângios e dos gametângios (Huang et al., 2002), favorecendo a fecundação cruzada e evitando a geitonogamia (Bertin, 1993).

No gênero Sagittaria são encontrados diferentes sistemas reprodutivos. A maioria das espécies é monóica, porém encontra-se andromonoicia em $S$. guayanensis e $S$. montevidensis subsp. calycina (Barrett et al., 2000), subandrodioicia em S. lancifolia subsp. lancifolia (Muenchow, 1998) e dioicia em S. latifolia (Wooten, 1971). Barrett et al. (2000) relatam que as únicas espécies anuais no gênero são andromonóicas, ou seja, as flores nos nós basais das inflorescências são perfeitas, produzindo um anel de estames funcionais ao redor do domo carpelar e numerosas flores microsporangiadas em posições terminais da inflorescência. Segundo os mesmos autores, como essas espécies são plantas daninhas e infestam campos de arroz, parece adequado que flores biesporangiadas tenham sido selecionadas para garantir a ocorrência de reprodução sexuada de seus gametófitos.

A esporidade da espécie tem uma expressão variável, dependendo das condições de vida da planta, comparando o seu ambiente natural e em condições de invasora, podendo apresentar maior número de flores megasporangiadas quando expostas a este último ambiente (Figura 2b).

Nas espécies monóicas Sagittaria sagittifolia e $S$. trifolia, foi observado que plantas menores apresentaram inflorescências apenas com flores microsporangiadas e, com o aumento da estatura da planta, houve a formação de flores micro e megasporangiadas. Quanto maior o tamanho da planta, maior número de flores megasporangiadas foi produzido (Huang et al., 2002; Dorken \& Barrett, 2003).

Trabalhos sobre a plasticidade fenotípica dos órgãos vegetativos e reprodutivos de $S$. lancifolia e $S$. latifolia, sob diferentes condições nutritivas, demonstraram que um maior número de inflorescências e uma maior produção de flores megasporangiadas, respectivamente, foram produzidos nas concentrações mais altas de fertilizantes (Richards \& Ivey,
2004; Dorken \& Barrett, 2004). A produção de flores megasporangiadas em $S$. montevidensis e, conseqüentemente, de aquênios parece ser favorecida com a aplicação de nutrientes ao solo.

Dentre os métodos de controle de plantas daninhas na cultura do arroz irrigado, impedir a produção de sementes, como medida preventiva, destaca-se como o mais eficiente, pois para a maioria das plantas daninhas da cultura esta estratégia representa o principal meio de reinfestação (SOSBAI, 2005). Ainda, no cultivo do arroz geralmente são realizadas diversas intervenções, especialmente mecânicas, o que dificulta o estabelecimento de plantas de sagitária como plantas perenes.

Associando-se essas informações à possível existência de uma relação tamanho-dependente relacionada ao porte da planta e ao número de flores megasporangiadas, sugere-se como possibilidade de manejo o controle localizado, nas bordas das taipas (leiveiros) e nos canais de irrigação e drenagem das lavouras, pois essas áreas favorecem o estabelecimento de plantas perenes com órgãos de reserva. Assim, a interrupção dos ciclos de multiplicação e disseminação dessas plantas permite a diminuição da dispersão de sagitária nas lavouras orizícolas e, com isso, há menor necessidade de adoção de medidas de controle.

Além disso, a drenagem da área de cultivo e dos canais de irrigação, na entressafra, constitui-se em procedimento eficaz, cuja resultante é a redução da proliferação da espécie, viabilidade do banco de semente no solo e infestação da área nos anos seguintes.

A presença de lâmina d'água favorece a germinação das sementes de sagitária. $\mathrm{O}$ aumento da profundidade de submersão incrementou a estatura da planta devido ao maior alongamento dos pecíolos das folhas espatuladas e sagitadas. Variação na profundidade da lâmina de água não modificou o número de plantas, a massa seca, o número de folhas e de raízes, o tamanho da folha linear e o tamanho da lâmina foliar espatulada e sagitada e do escapo floral das plantas de $S$. montevidensis. As folhas de $S$. montevidensis de mesmo tipo morfológico, quando desenvolvidas nas profundidades de água testadas, não diferiram histologicamente. 


\section{LITERATURA CITADA}

ARMSTRONG, W.; BRËNDLE, R.; JACKSON, M. B Mechanisms of flood tolerance in plants. Acta Bot. Neerl., v. 43, p. 307-358, 1994.

BARRETT, S. C. H.; BAKER, A.; JESSON, L. K. Mating strategies in monocotyledons. In: WILSON, K. L: MORRISON, D. A. (Eds.). Monocots: Systematics and evolution. Melbourne: CSIRO, 2000. p. 258-269.

BERTIN, R. I. Incidence of monoecy and dichogamy in relation to self-fertilization in angiosperms. Am. J. Bot., v. 80, n. 5 , p. $557-560,1993$.

BRÄNDLE, R. A. Flooding resistance of rhizomatous ambphibious plants. In: JACKSON, M. M.; DAVIES, D D.; LAMBERS, H. (Eds.). Plant life under oxygen deprivation. The Hague: SPB, 1991. p. 35-46.

CHUNG, Y. R. et al. Potential of an indigenous fungus, Plectosporium tabacinum, as a mycoherbicide for control of arrowhead (Sagittaria trifolia). Plant Dis., v. 82, p. 657-660, 1998.

CONCENÇO, G. et al. Aspectos da resistência de Sagittaria montevidensis ao herbicida pirazosulfuron-ethyl inibidor da ALS. Planta Daninha, v. 25, n. 1, p. 187-194, 2007.

COOPS, H.; van den BRINK, F. W. B.; van der VELDE, G. Growth and morphological responses of four helophyte species in an experimental water-depth gradient. Aquat. Bot., v. 54, n. 1, p. 11-24, 1996

COTHER, E. J.; GILBERT, R. L. Pathogenicity of Rhynchosporium alismatis and its potential as a mycoherbicide on several weed species in the Alismataceae

Austr. J. Exp. Agric., v. 34, p. 1039-1042, 1994.

DORKEN, M. E.; BARRETT, S. C. H. Gender plasticity in Sagittaria sagittifolia (Alismataceae), a monoecious aquatic species. Plant Syst. Evol., v. 237, n. 1, p. 99-106, 2003.

DORKEN, M. E.; BARRETT, S. C. H. Sex determination and the evolution of dioecy from monoecy in Sagittaria latifolia (Alismataceae). Proc. R. Soc. B., v. 271, p. 213219, 2004.

FEDER, N.; O'BRIEN, T. P. Plant microtechnique, some principles and new methods. Am. J. Bot., v. 55, n. 1, p. 123 $142,1968$.

GABRIEL, B. L. Biological electron microscopy. New York: Van Nostrand Reinhold, 1982. 264 p.

GERRITS, P. O.; SMID, L. A new, less toxic polymerization system for the embedding of soft tissues in glycol methacrylate and subsequent preparing of serial sections. J. Microsc., v. 132, n. 1, p. 81-85, 1983
GIBSON, K. D. et al. California arrowhead is a weak competitor in water-seeded rice. Weed Sci., v. 49, p. 381384, 2001.

HOWARD, R. J.; MENDELSSOHN, I. A. Effect of increased water depth on growth of a common perennial fresh-water-intermediate marsh species in coastal Louisiana. Wetlands, v. 15, n. 1, p. 82-91, 1995.

HUANG, S. Q. et al. Gender variation of sequential inflorescences in a Monoecious plant Sagittaria trifolia (Alismataceae). Ann. Bot., v. 90, p. 613-622, 2002.

ISHII, J.; KADONO, Y. Sexual reproduction under fluctuating water levels in an amphibious plant Schoenoplectus lineolatus (Cyperaceae): A waiting strategy? Limnology, v. 5, n. 1, p. 1-6, 2004

JENSEN, W. A. Botanical histochemistry: principles and practice. San Francisco: W. H. Freeman, 1962. 408 p.

JIANG, M.; KADONO, Y. Seasonal growth and reproductive ecology of two threatened aquatic macrophytes, Blyxa aubertii and B. echinosperma (Hydrocharitaceae), in irrigation ponds of south-western. Ecol. Res., v. 16, n. 2, p. 249-256, 2001a.

JIANG, M.; KADONO, Y. Seasonal growth and reproductive ecology of two threatened aquatic macrophytes, Blyxa aubertii and B. echinosperma (Hydrocharitaceae), in irrigation ponds of south-western. Ecol. Res., v. 16, p. 687-695, 2001b.

JOHANSEN, D. A. Plant microtechnique. New York: McGraw-Hill, 1940. 523 p.

KAUL, R. B. Foliar plasticity and life-history characteristics in Sagittaria (Alismataceae). Am. J. Bot., v. 74, n. 5, p. 739-739, 1987.

KELLOGG, C. H.; BRIDGHAM, S. D.; LEICHT, S. A Effects of water level, shade and time on germination and growth of freshwater marsh plants along a simulated successional gradient. J. Ecol., v. 91, n. 2, p. 274-282, 2003.

KRAMER, P. J.; BOYER, J. S. Water relations of plants and soils. San Diego: Academic Press, 1995. 495 p.

LENSSEN, J. P. M.; TENDOLLE, G. E.; BLOM, C. W. P. $\mathrm{M}$. The effect of flooding on the recruitment of reed marsh and tall forb plant species. Plant Ecol., v. 139, n. 1, p. 1323,1998

LIU, C. H.; LI, W.; CHENG, Y. The seed bank in a subtropical freshwater marsh: implications for wetland restoration. Aquat. Bot., v. 81, n. 1, p. 1-11, 2005. 
MARTIN, S. B.; SHAFFER, P. Sagittaria biomass partitioning relative to salinity, hydrologic regime, and substrate type: Implications for plant distribution patterns in Coastal Louisiana, United States. J. Coast. Res., v. 21, n. 1, p. 167-174, 2005.

McDOWELL, E. M; TRUMP, B. Histological fixatives for diagnostic light and electron microscopy. Arch. Path., v. 100, p. $405-414,1976$

MOORE, D. R. L.; KEDDY, P. A. Effects of a water-depth gradient on the germination of lakeshore plants. Can. J. Bot., v. 66, p. 548-552, 1988.

MUENCHOW, G. E. Subandrodioecy and male fitness in Sagittaria lancifolia subsp. lancifolia (Alismataceae). Am. J. Bot., v. 85, n. 4, p. 513-520, 1998.

NISHIHIRO, J. et al. Germination characteristics of lakeshore plants under an artificially stabilized water regime. Aquat. Bot., v. 79, n. 4, p. 333-343, 2004.

NOLDIN, J. A.; EBERHARDT, D. D.; KNOBLAUCH, R. Resistência de Sagittaria montevidensis a herbicidas: primeiras evidências. In: CONGRESSO BRASILEIRO DE ARROZ IRRIGADO, 1.; REUNIÃO DA CULTURA DO ARROZ IRRIGADO, 23., 1999, Pelotas. Anais... Pelotas: Embrapa-CPACT, 1999. p. 566-569.

NOLDIN, J. A.; EBERHARDT, D. S. Controle de sagitária resistente a herbicidas com aplicações em pulverização. In: CONGRESSO BRASILEIRO DE CIÊNCIA DAS PLANTAS DANINHAS, 22., 2000, Londrina. Resumos... Londrina: Sociedade Brasileira da Ciência das Plantas Daninhas, 2000. p. 515.

PACINI, E.; FRANCHI, G. G. Types of pollen dispersal units in monocots. In: WILSON, K.L.; MORRISON, D.A. (Eds). Monocots: Systematics and evolution. Melbourne: CSIRO, 2000. p. 295-300.

PAILLISSON, J. M; MARION, L. Can small water level fluctuations affect the biomass of Nymphaea alba in large lakes? Aquat. Bot., v. 84, p. 259-266, 2006.

PIMENTA, M. L. Biologia da reprodução de Sagittaria lancifolia L. susp. lancifolia - Alismataceae. 1992. 89 f. Dissertação (Mestrado em Ciências Biológicas - Botânica) Universidade Federal do Rio de Janeiro - Museu Nacional, Rio de Janeiro, 1992.

PITT, W. M. et al. Infection process of Plectosporium alismatis on the host and non-host species in the Alismataceae. Mycol. Res., v. 108, n. 7, p. 837-845, 2004.
REGO, S. C. Alismataceae Ventenat no Rio Grande do Sul. 1988. 120 f. Dissertação (Mestrado em Botânica) Universidade Federal do Rio Grande do Sul, Porto Alegre, 1988.

RESENDE, U. M. Análise estrutural de Neptunia plena (L.) Benth. (Mimosaceae) em ambiente inundado e livre de inundação, no pantanal mato-grossense, município de Corumbá, Mato Grosso do Sul. 1996. $131 \mathrm{f}$. Dissertação (Mestrado em Botânica) - Universidade Federal do Paraná, Curitiba, 1996.

RICHARDS, J. H.; IVEY, C. T. Morphological plasticity of Sagittaria lancifolia in response to phosphorus. Aquat. Bot., v. 80, n. 1, p. $53-67,2004$

SANINT, L. R. Evolución tecnológica, perspectivas futuras y situación mundial del arroz. In: REUNIÃO DA CULTURA DO ARROZ IRRIGADO, 22., 1997, Balneário Camboriú. Palestras... Itajaí: EPAGRI, 1997. p. 7-30.

SCREMIN-DIAS, E. Caracterização morfo-anatômica dos órgãos vegetativos de Echinodorus paniculatus Micheli e Echinodorus tenellus (Mart.) Buchenau (Família Alismataceae), durante o período da cheia e da seca no pantanal sul-mato-grossense. 2000. $231 \mathrm{f}$. Tese (Doutorado em Ciências Biológicas - Botânica) - Instituto de Biociências da Universidade de São Paulo, São Paulo, 2000.

SOCIEDADE SUL-BRASILEIRA DE ARROZ IRRIGADO - SOSBAI. Arroz irrigado: recomendações técnicas da pesquisa para o sul do Brasil. Santa Maria: 2005. p. 115136.

TAMURA, S.; KURAMOCHI, H.; ISHIZAWA, K Involvement of calcium ion in the stimulated shoot elongation of arrowhead tubers under anaerobic conditions. Plant Cell Physiol., v. 42, p. 717-722, 2001.

van den BRINK, F. W. B. et al. Effects of substrate parameters on growth responses of eight helophyte species in relation to flooding. Aquat. Bot., v. 50, p. 79-97, 1995.

WHITE, S. D.; GANF, G. G. A comparison of the morphology, gas space anatomy and potential for internal aeration in Phragmites australis under variable and static water regimes. Aquat. Bot., v. 73, n. 2, p. 115-127, 2002.

WOOTEN, J. W. Monoecious and dioecious conditions in Sagittaria latifolia L. (Alismataceae). Evolution, v. 25, n. 3, p. $549-553,1971$.

WOOTEN, J. W. Variations in leaf characteristics of six species of Sagittaria (Alismataceae) caused by various water levels. Aquat. Bot., v. 23, p. 321-327, 1986. 